\title{
Italy Is Fragile: Soil Consumption and Climate Change Combined Effects on Territorial Heritage Maintenance
}

\author{
Lorenzo Fabian and Mattia Bertin *
}

EPiC Earth and Polis Research Centre, Università Iuav di Venezia, 30123 Venice, Italy; lfabian@iuav.it

* Correspondence: mbertin@iuav.it; Tel.: +39-333-4649-785

\begin{abstract}
The article looks for relations between growth of expanding cities, number of catastrophes and reduction of inhabitants in inland regions. The study explores these aspects through cartographic readings aimed at highlighting the relationship between soil consumption, the abandonment of peripheral areas, and environmental risks due to floods, landslides and earthquakes. The research analyzes the whole of Italy as a case study between 1990 and 2019 to get an accurate interpretation of the relations between these phenomena. The conclusions alert us to the need to redirect Italy's development and its resilience projects. The study outlines the need of a re-living plan for Italian inner areas. It would be the only security process really capable of taking care of the territory.
\end{abstract}

Keywords: climate change; disaster; soil consumption

Citation: Fabian, L.; Bertin, M. Italy Is Fragile: Soil Consumption and Climate Change Combined Effects on Territorial Heritage Maintenance. Sustainability 2021, 13, 6389. https:// doi.org/10.3390/su13116389

Academic Editors: Edward Blakely, Peter Kresl, Francesco Musco and Richard $\mathrm{Hu}$

Received: 14 April 2021

Accepted: 29 May 2021

Published: 4 June 2021

Publisher's Note: MDPI stays neutral with regard to jurisdictional claims in published maps and institutional affiliations.

Copyright: (c) 2021 by the authors. Licensee MDPI, Basel, Switzerland. This article is an open access article distributed under the terms and conditions of the Creative Commons Attribution (CC BY) license (https:// creativecommons.org/licenses/by/ $4.0 /)$.

\section{Introduction}

Italy is currently experiencing the effects of an expansive building cycle that took place between 1990 and 2006. This process has led to an increase in construction and the consumption of soil. This expansion has taken place in areas which have been mainly removed from agricultural use, in the richest areas of the country. The expansion has consolidated metropolitan areas and existing settlements, reinforcing the urban sprawl. This phenomenon has occurred above all in the great plains of northern and central Italy near the major gateways. These profound transformations have not only affected Italian territory through expansion. In its final phase (from 2008), the great 'building cycle of expansion' [1] has also produced the abandonment, underuse, or disuse of buildings, infrastructures, and built-up areas. We can view this as an expression of 'growth increasingly decoupled from development, which has left rubble on the ground' [2].

In the same years, the emergencies and disasters that have affected the Italian landmass [3] justified territorial policy choices. These policies have tended to situate territorial planning projects in a framework of emergency management and fast recovery. Urgency and emergency, removed from their strictly professional context, have caused a renunciation of the design and planning perspective. The rhetoric of emergency has tended to occlude the actual character of Italian territory, which by its nature is fragile, unstable, and, for the most part, very difficult to inhabit. The results of these policies can be seen in three ways. The first refers to a remedial territorial policy aimed at the rapid resolution of events without a deep understanding of local constraints. A second is concerned with the processes of city expansion in the most urbanized parts of the country with the consequence of extensive soil consumption. A third trend, in peri-urban and inland areas, is the lack of medium- and long-term planning for the maintenance of existing territorial infrastructures, such as wooded slopes and water networks, resulting in a widespread increase in fragile conditions. Climate change is acting as a catalyst for this setting of events, causing a significant increase in the number of floods, run-offs, and minor landslides on a territorial scale, testing territorial capacity for adaptation and resilience. [4]

This article explores the evolution of Italian territory and the correlated increase of risk through cartographic readings. The maps produced aim to highlighting the relation- 
ship between soil consumption, the abandonment of peripheral areas, and environmental risks due to floods, landslides and earthquakes. The period discussed is that of the sixth building cycle, between 1995 and 2010, which was the most significant urban expansion since the post-war period in terms of intensity and duration, as identified in the Cresme Institute's report on the construction market [1]. The paper will demonstrate the correlation of several fundamental issues: the expansion of the built environment and the production of urban waste areas; the abandonment of peripheral territories; and the risks of flooding, earthquakes, landslides and overflowing, derived from the national database edited by the Istituto Superiore Per la Ricerca Ambientale (Higher Institute for Environmental Research) [3].

By overlapping the real estate market and territorial risks, the paper aims to verify the correlations between these processes. This will be accomplished starting from an empirical geostatistical analysis, aimed at the construction of interpretative maps of the territory. As we will see in the conclusions, there are strong correlations in at least two possible ways between these aspects: (1) the abandonment of inland areas, the increase in eventrelated damage and the consequent increase in underuse phenomena, and (2) between soil consumption in metropolitan areas and the increase in disaster risks in these territories. The research shows the need to direct the real estate market in the dual directions of reducing soil consumption in metropolitan areas, and towards housing and the consequent maintenance of inland areas at the resumption of development.

This last aspect, which is the focus of the paper, appears to be relevant for issues purely related to the enhancement of the widespread 'territorial heritage' that characterizes Italian territory [5]. Moreover, this is also crucial to protect urbanization processes in large urban centres. The article starts from a conception of climate change as a global catastrophe [6,7]. The authors interpret climate change as a global switch of paradigms and view the crises of the last twenty years as a tool for interpreting the evolution of national systems. This consideration allows us to grasp timely events as part of a global evolutionary process, which must be recognized and addressed in its entirety. The article therefore analyzes how alternating cycles of expansive and deflationary building processes have acted in relation to local manifestations of this global catastrophe. The study will provide an important tool for orienting the national climate strategy. The study will also provide a replicable example of the approach that could be employed in similar countries in order to create and validate statistical data.

\section{Theoretical Framework}

The research is based on four main theoretical ideas. The first is related to Edward Blakely's work on social-economic repositioning and his approach to regional studies. The second is Peter Meyer's report on the need for incremental financing for climate change adaptation in cities. The third is the work on pre-disaster recovery planning by Philip Berke. The fourth is the change of order in the local planning matrix proposed by Mattia Bertin, Lorenzo Fabian, and Francesco Musco on the basis of extensive literature produced internationally on these issues.

Blakely's theory of repositioning, which finds its operational matrix in the experience of New Orleans, [8,9] reminds us how necessary it is to rethink the development of a territory from what it might represent in a global system in the future, rather than what it may have been in the past. This thought intersects with several articles that have appeared since Hurricane Katrina. These articles demonstrate how plans and policies impacted in Katrina disaster reducing the local resilience [10,11]. The overstraining of an area, its lack of attractiveness for residency and its inability to develop new economies signal its propensity for disaster $[12,13]$. This attention leads us to reflect on what relationship there is between an increasingly frequent number of disasters in Italy and a process of condensation of urban growth in some areas of the country [14].

The second stimulus came from Meyer's research on financing cities to fight climate change [15]. The author shows how a heavy, integrative involvement of private and non- 
routine finance is needed for an effective fight against climate impacts at the local scale. [16] We find interesting cases of this approach in Italy: Milan, Turin, the Mantua-ModenaBologna axis, the Venice Quadrilateral [7,17]. However, these urban systems represent the areas of greatest economic growth and transformation in the country [18]. First, we asked ourselves what was happening from the point of view of the effects of disaster events in areas not capable of this type of investment attraction. Second, we asked ourselves how disasters occurred in less attractive areas might had side effect on the most attractive areas of the Country.

In order to understand the relationships between urban transformation, disaster, and adaptation opportunities, we referred to the work of Philip Berke. In particular, we borrowed from his work a perspective on adaptation that does not start from the built environment, but from the potential disaster $[19,20]$. This paradigm shift makes it possible to overcome a conservative status quo approach, which, in a national system such as Italy that is so stratified in heritage issues can prevent one from understanding the potential damage of the evolutions underway [21].

Finally, Italian research on the reversal of the local planning hierarchy, which brings the issue of risk planning to the top of city design, delivers us the opportunity to look at local development precisely from those impacts that Berke says are the key to an interpretation of development $[7,19]$. Contemplating the design of the country system from the recognition of national risk chains and understanding how they correlate with residential flows can effectively challenge current climate change management strategies [22,23].

Finally, our research on marginality in Italy, moves from a literature that is consolidating around these themes. Our most relevant reference has been Michelangelo Russo's work on fragility, abandonment, and territorial metabolism, published in a series of reports and studies that suggest an agenda for Italian cities and territories in order to deal with risk and land abandonment. These reports and studies suggest a query of the relationship between building processes in Italy and the change to territorial risks [24-27]. To emphasize the urgency of this point of view we should also mention the numerous environmental studies and research projects carried out in Italy in recent years. Those that we have consulted have dealt with: the strategic importance of territorial maintenance of non-urbanized areas to counter territorial fragility $[28,29]$; the value of policies and projects aimed at valorizing and combatting the abandonment and marginalization of inland areas [30-33]; the valorization of diffused territorial heritage and of environmental resources $[5,34]$.

\section{Materials and Methods}

We proceeded in three steps while developing research: reading the field, which was dedicated to representing official national statistical data; overlapping the data, where we searched for empirical correspondences; and testing in depth, where we explored reliability (Figure 1).

In order to conduct the three research steps, we investigated the issues and mentioned their cartographic representation at the country scale, relying on four categories of data: soil consumption phenomena; abandonment; geological, hydrogeological, and hydraulic risks; and the seismic events which had occurred.

We made these observations using data collected officially by the government's statistical and environmental observatories. We used five sources of data, all recognized by SISTAN, the National Statistical System of data collection and evaluation. The data on population are the results of the 2012 ISTAT - the National Institute of Statistics census (the last complete census of the Italian population) and subsequent sectoral surveys by the same institute; the reference universe is always the entire Italian population collected by census (the homogeneous fractions of a municipality) from all Italian municipalities. Data on building expansion were provided by CRESME, a study centre dedicated to describing and forecasting trends in the economy and the construction market; the universe consisted of all Italian municipalities and corresponds to the sample. 


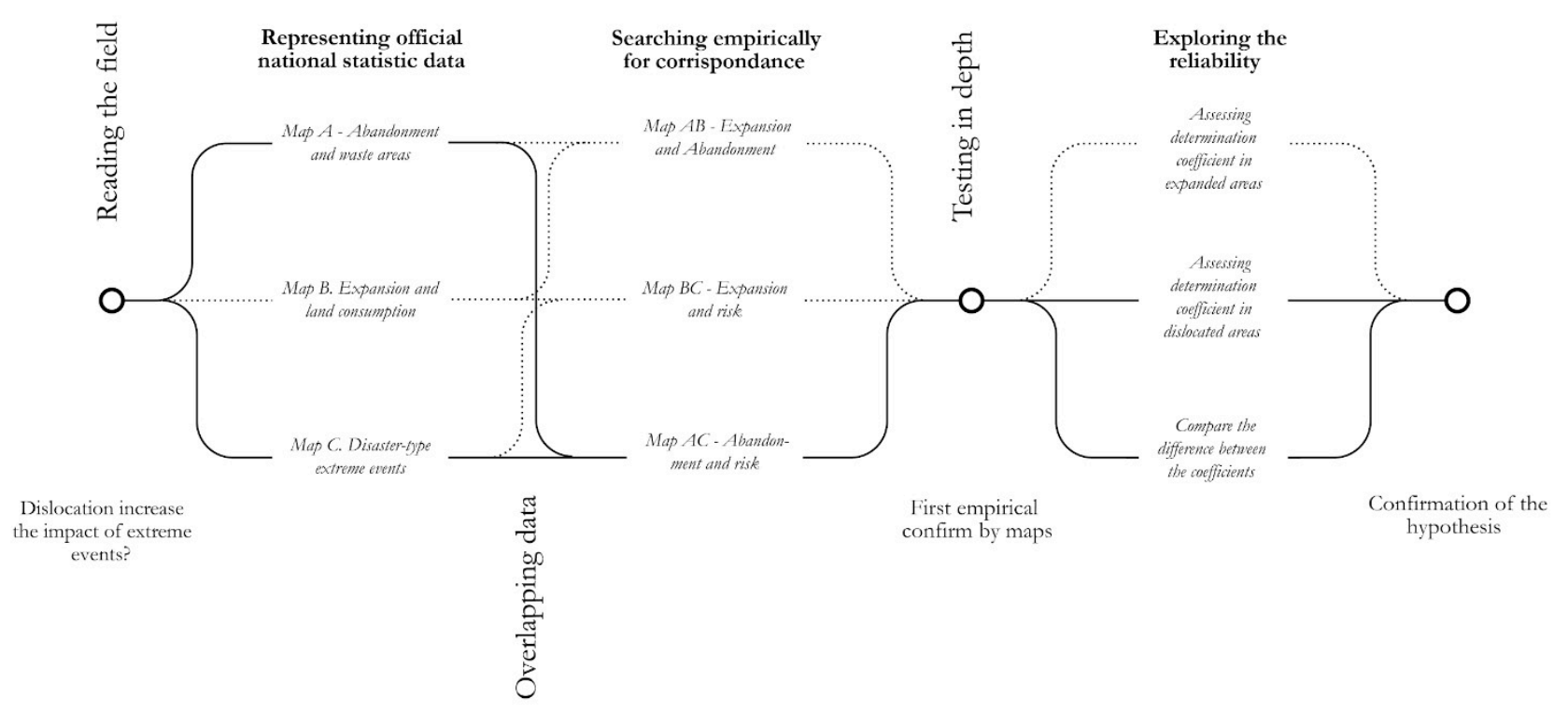

Figure 1. Methodology flowchart.

The data on soil consumption are the result of comparisons on land use in the period considered (1990, 2000, 2006, and 2012) provided by the European initiative Corine Land Cover (CLC) for the detection and monitoring of land cover and land use characteristics, in order to verify the dynamics of the state of the environment. The data on earthquakes in Italy come from the INGV - the National Institute of Geophysics and Volcanology database, which collects and georeferences all the tremors that have occurred in Italy since 1 January 1985, both on the Richter and Mercalli scales. The data on hydraulic and hydrogeological risk, and on emergencies caused by it, are produced by ISPRA and collected by municipalities covering all the events that have occurred in Italy since 1951. Data on seismic risk are produced by INGV and agreed with the National Department of Civil Protection of the Presidency of the Council of Ministers (Table 1).

Table 1. Primary data sources used.

\begin{tabular}{lcccc}
\hline \multicolumn{1}{c}{ Theme } & Universe and Champion & Authority & Scale & Period \\
\hline Abandonment & 7900 municipalities & ISTAT & Census ISTAT & $1980-2012$ \\
Building expansion & 7900 municipalities & CRESME & Municipality & $1991-2012$ \\
Soil consumption & 7900 municipalities & CLC & Municipality & $2000-2019$ \\
Municipalities at & 7900 municipalities & ISPRA & Municipality & $1951-2017$ \\
hydrogeological risk & 7900 municipalities & INGV & Municipality & $1980-2021$ \\
Municipalities at seismic risk & 7900 municipalities & ISPRA & Municipality & $1990-2021$ \\
Energy consumption & 98,008 seismic tremors & INGV & 50 metres & $1985-2021$ \\
Seismic events (Richter) & 285,909 local events & INGV & Municipality & $2007-2018$ \\
Seismic events (Mercalli) & & & &
\end{tabular}

\subsection{Reading the Field}

In the first step we collected these data and represented them in single-topic maps on a national scale through GIS mapping and georeferenced data-visualization. This resulted in three basic maps:

1. Map A-Nationwide representation of abandonment and the creation of large waste areas. In the map we show:

- Unused buildings. The data refers to buildings recognized by the 2011 ISTAT census as 'buildings/complexes not yet ready for use as living accommodation and/or for the production of goods or services because they are under construction; buildings/complexes no longer suitable for use as living accommodation and/or for the production of goods or services because they are falling down, in disrepair and the like'. (ISTAT 2011); 
- Underused dwellings. The data refers to dwellings where it is not possible to recognize the characteristics of 'dwellings occupied by persons who have their usual residence in them, even if temporarily absent [...]' (ISTAT 2011);

- Abandoned sites. Locations with only unused buildings (ISTAT 2011, statistical glossary, entry 'unused building or complex of buildings');

- Localities without residents. This shows all localities where the resident population, specifically 'persons having their usual residence in the municipality' (ISTAT 2011, statistical glossary, entry 'resident population'), is zero;

- Municipalities classified as intermediate, peripheral and ultra-peripheral by the National Strategy for Inland Areas (SNAI 2013).

2. Map B-Expansion and soil consumption. The map shows the soil consumption calculated from a comparison of land use maps based on satellite images from 1990, 2000, and 2006. (CLC 1990/2000/2006) (The National Strategy for Inland Areas (SNAI 2013) identifies inland areas as those which are significantly distant from the centers of supply of essential services (education, health and mobility). The inland areas are divided into intermediate, peripheral and ultra-peripheral areas. This category account approximately $53 \%$ of the Italian municipalities (4261). The inland areas account $23 \%$ of the Italian population according to the last census (13.5 million inhabitants)).

3. Map C-Extreme events of a catastrophic character (hydraulic, hydrogeological, seismic). We have superimposed the phenomena of overflow, flood, SLR, landslides, and earthquakes to create a map of land impacts. The map shows:

- Areas subject to landslides; source: ISPRA (Italian National Institute for Environmental Protection and Research);

- $\quad$ Areas subject to medium-high risk of flooding; source: ISPRA (Italian National Institute for Environmental Protection and Research);

- Areas subject to polygonal and superficial landslides; source: ISPRA (Italian National Institute for Environmental Protection and Research);

- Earthquakes from the year 1000 to 2014 of Richter magnitude greater than 5, from the parametric catalogue of Italian territories (source: reworked by the National Institute of Geophysics and Volcanology);

- Seismogenic faults; source: European Seismogenic Faults Database.

These three maps provided a first basic documentation on which to develop subsequent comparisons.

\subsection{Overlapping the Data}

In the second step, we carried out a process of empirical comparison between the maps to identify possible correspondences. These correspondences suggested the simple coexistence of phenomena. First, we compared the data, and collected the aforementioned processes in a univocal format. We compared each of the maps with the other two. This produced three correspondence maps:

1. Map AB-Soil consumption and abandonment. The first correspondence map investigates the coexistence or differential location of soil consumption and land abandonment phenomena. We developed the cartographic comparison of soil consumption and abandonment phenomena between 1990 and 2009, corresponding to the expansive building cycle, and then in control form from 2008 to 2019. This classification makes it possible to map the major flows of capital and residents between different areas of the country, thus establishing vectors of investment and depopulation.

2. Map BC-Soil consumption and extreme events. The second correspondence map investigates the increase, decrease, or non-correlation between the extreme events considered and the soil consumption processes since the last building expansion phase until today (1991-2019).

3. Map AC-Abandonment and extreme events. The third correspondence map investigates the increase, decrease, or non-correlation between the extreme events considered and 
the processes of land abandonment since the last expansionary building phase to date (1991-2019).

Step 2 led to two hermeneutic-empirical comparisons. The first was between the building process and the process of land abandonment by residents. The second was between the process of land abandonment and the number of catastrophic impacts that had occurred.

\subsection{Testing in Depth}

After the second step, we recognized a particularly significant phenomenon that we develop here in order to complete the presentation of the methodology: in Map BC Soil Consumption and Extreme Events, we recognized an increase in climate-change related impacts but not seismic ones; in Map AC, Abandonment and Extreme Events, seismic phenomena also increase if measured in Mercalli, and not only in completely uninhabited municipalities. This element, if confirmed experimentally, would be of great importance: it would show that the increase in impacts in Italy is not only linked to the increase in climate change phenomena but also has another origin. As is well known, the Mercalli-CancaniSieberg scale evaluates the intensity of an earthquake which, unlike the Richter scale, is carried out by observing the effects that an earthquake produces on people, things, and artefacts. It therefore depends on the level of anthropization and the state of maintenance of infrastructures and buildings in an area. This control has allowed us to establish whether the abandonment of the inner areas actually leads to an increase in the severity of the impacts on inhabited areas.

To assess a control of this factor, we selected two samples of municipalities defined by the National Strategy for Inner Areas. The first sample corresponds to municipalities classified as poles, i.e., the second class according to attractiveness (217 municipalities, see Table 2 p.7). The second sample corresponds to municipalities classified as peripheral, i.e., the penultimate class according to attractiveness (1522 municipalities). Although there are very different numbers of samples per class, the combined surface area and number of residents are comparable. This has allowed us to exclude cases of total abandonment and great acceleration in transformation, instead including two classes that are more representative of phenomena that are widespread on a national scale.

Table 2. Correlation between: municipalities classification in National Strategy for Inner Areas; \% of locations without inhabitants per municipality; \% of unused buildings per municipality.

\begin{tabular}{lcccc}
\hline \multicolumn{1}{c}{ Class } & $\begin{array}{c}\text { \% Location } \\
\text { without } \\
\text { Inhabitants }\end{array}$ & $\begin{array}{c}\text { Unused } \\
\text { Buildings }\end{array}$ & $\begin{array}{c}\text { Total } \\
\text { Buildings }\end{array}$ & $\begin{array}{c}\text { \% Unused } \\
\text { Buildings }\end{array}$ \\
\hline Ultraperipheral & $13 \%$ & $17,230.00$ & $248,957.00$ & $7 \%$ \\
Peripheral & $46 \%$ & $95,469.00$ & $1,296,140.00$ & $7 \%$ \\
Intermediate & $0 \%$ & $137,368.00$ & $2,251,405.00$ & $6 \%$ \\
Belt & $26 \%$ & $161,364.00$ & $3,359,258.00$ & $5 \%$ \\
Inter-municipal poles & $1 \%$ & $14,917.00$ & $368,249.00$ & $4 \%$ \\
Poles & $14 \%$ & $93,407.00$ & $2,593,382.00$ & $4 \%$ \\
Internal areas & $59 \%$ & $250,067.00$ & $3,796,502.00$ & $7 \%$ \\
Central areas & $41 \%$ & $269,688.00$ & $6,320,889.00$ & $4 \%$ \\
\hline
\end{tabular}

We counted the number of municipalities affected by earthquakes of Mercalli intensity greater than 2 and less than 9 per class for each year from 2007 to 2017 . We calculated the coefficient of determination R2 of the 2007-2017 sequence for each of the two classes of samples. Finally, we compared the R2 coefficient of the two sequences to understand if indeed there were mathematically relevant different behaviours that could suggest a connection between land abandonment and increased seismic impacts in municipalities with no inhabitants. 


\section{Results}

The methodology allowed us to frame the Italian country system by aggregating and relating phenomena that are often studied independently. In this section we see the results of the methodology arising from the three steps followed, while leaving as much as possible to the discussion section.

\subsection{Reading the Field}

The first step of analysis provided us with solid maps, which contained a great concentration of information homogeneously distributed over the whole Italian territory. Each of the maps allows a synthetic reading of the phenomenon, with a series of elements which are able to orient sectoral policies for the reduction of risk and abandonment. In particular we note three results emerging from the separate analysis of the three maps. In the next pages we will see in detail the frames that emerged from this first step.

From the analysis of the three maps and the outcome of the first step (see the Table 2 for a presentation of this step results), we can observe some initial results:

1. The spaces of abandonment correspond to the peripheral areas recognized by the National Strategy for Inner Areas with a very-high level of overlapping. Most of these territories are located in mountain or foothill environments, in the Alps and Apennines, and on islands. This confirmation, however, calls into question the results of the policies associated with the National Strategy for Inner Areas, suggesting a substantial ineffectiveness of the approach used until now (Figures 2 and 3).

2. The spaces of expansion overlap with the aggregation poles recognized by the National Strategy for Inner Areas with a very-high degree of coherence. Most of them correspond to the large industrial and service centres of the North and Centre (Table 2).

3. Seismic events are located all over the country, but with a higher density in the Apennine and pre-alpine areas. Landslide and geological instability events are distributed over the same areas. Most hydraulic events, on the other hand, occur in densifying lowland areas (Figure 4).

Map A has been used to study Nationwide representation of abandoned and large waste areas (Figure 2). In this map we find:

- Unused buildings, represented by black circles proportional in size to the number of total buildings (unused buildings/total buildings), spaced on the centroid of the reference census.

- Abandoned localities, where only unused buildings are present, represented by red circles whose radius is proportional to the number of buildings in the locality.

- Inland areas, recognized by SNAI (see note at p. 5) and represented with black areas on the map.

The data is represented by circles with a radius proportional to the hectares of soil consumed spatialized in the centroid of the corresponding cartographic polygon calculated from a comparison of land use maps from satellite images (CLC 1990/2000/2006).

Map B and Table 3 describe the overlapping of expansion and soil consumption.

Table 3. Percentages of consumed soil in land use classes: the artificial surfaces with detail at Corine Land Cover (CLC) level 3.

\begin{tabular}{cllll}
\hline \multirow{2}{*}{ CLC Code } & $\begin{array}{c}\text { Typology of Land Use Consumed } \\
\text { Soil (\%) in Year: }\end{array}$ & $\mathbf{1 9 9 0}$ & $\mathbf{2 0 0 0}$ & $\mathbf{2 0 0 6}$ \\
\hline $\mathbf{1 1 1}$ & Continuous urban fabric & 82.4 & 83.2 & 84.8 \\
$\mathbf{1 1 2}$ & Discontinuous urban fabric & 61.0 & 61.9 & 64.1 \\
$\mathbf{1 2 1}$ & Industrial or commercial areas & 70.6 & 72.0 & 73.6 \\
$\mathbf{1 2 2}$ & Road and rail networks and & 66.0 & 65.4 & 69.4 \\
$\mathbf{1 2 3}$ & associated spaces & 85.3 & 86.3 & 86.2 \\
$\mathbf{1 2 4}$ & Port areas & 29.9 & 30.5 & 37.2 \\
\hline
\end{tabular}




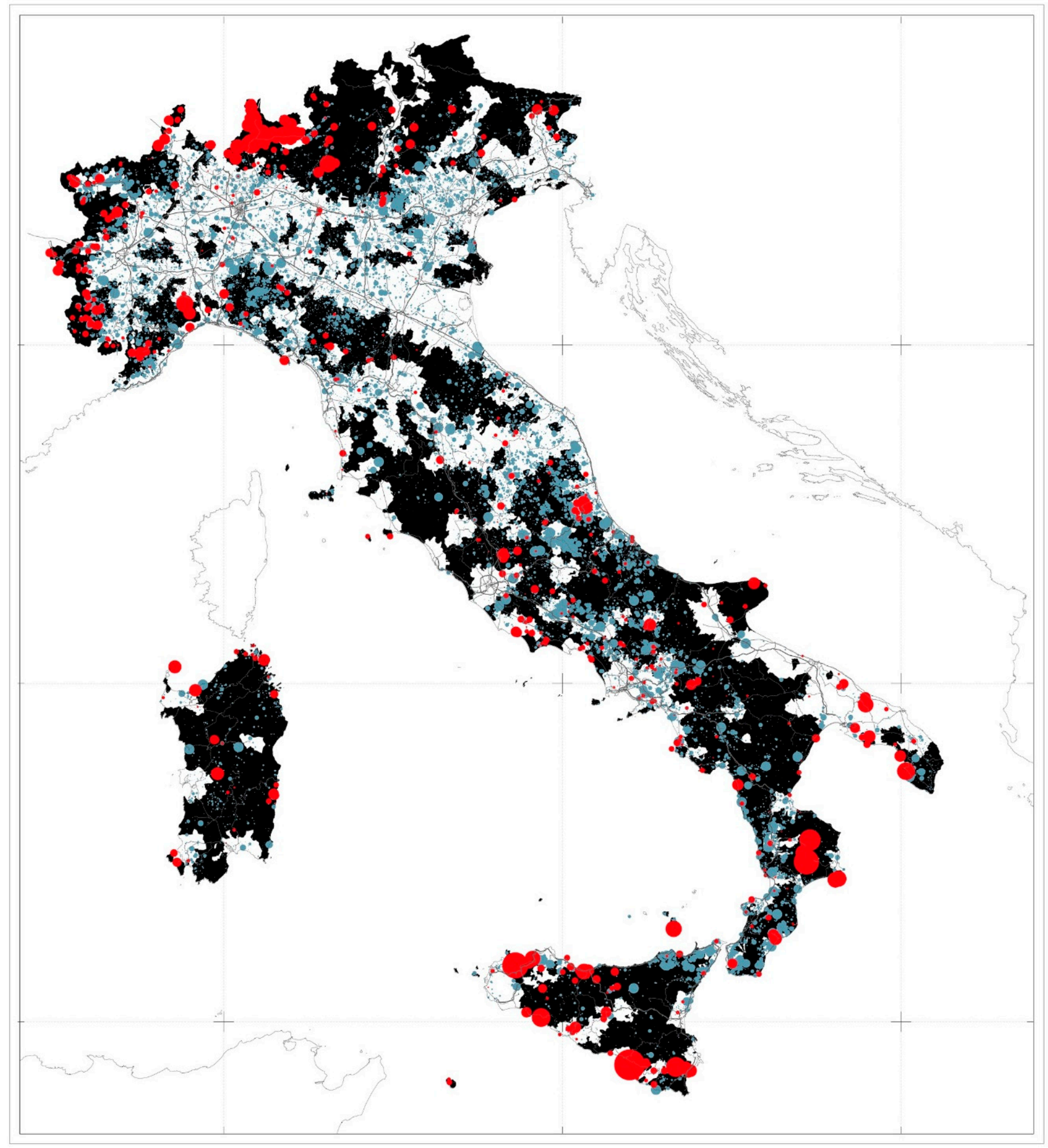

Figure 2. Map A-Nationwide representation of abandoned and large waste areas. 


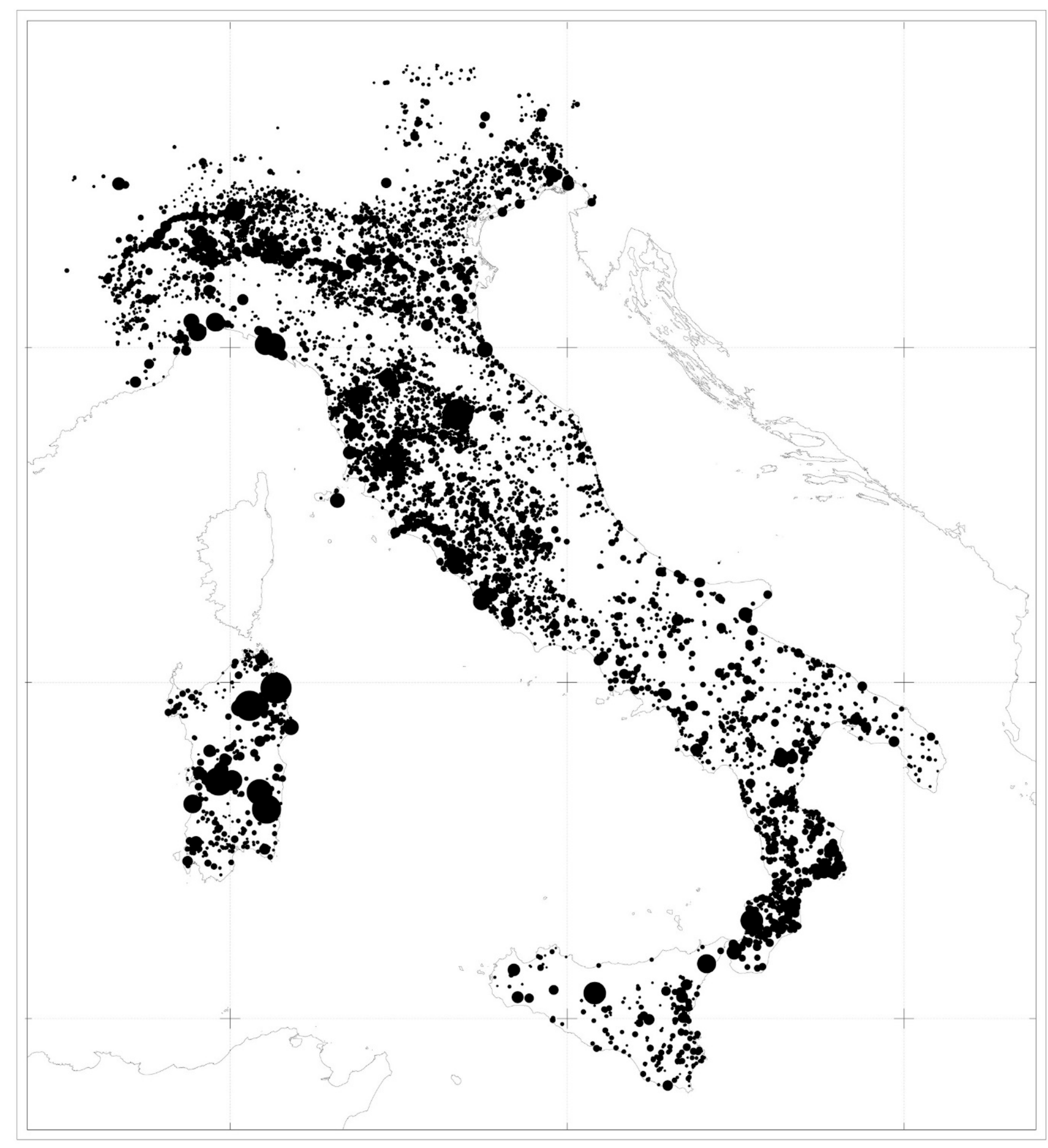

Figure 3. Map B-Expansion and soil consumption. 


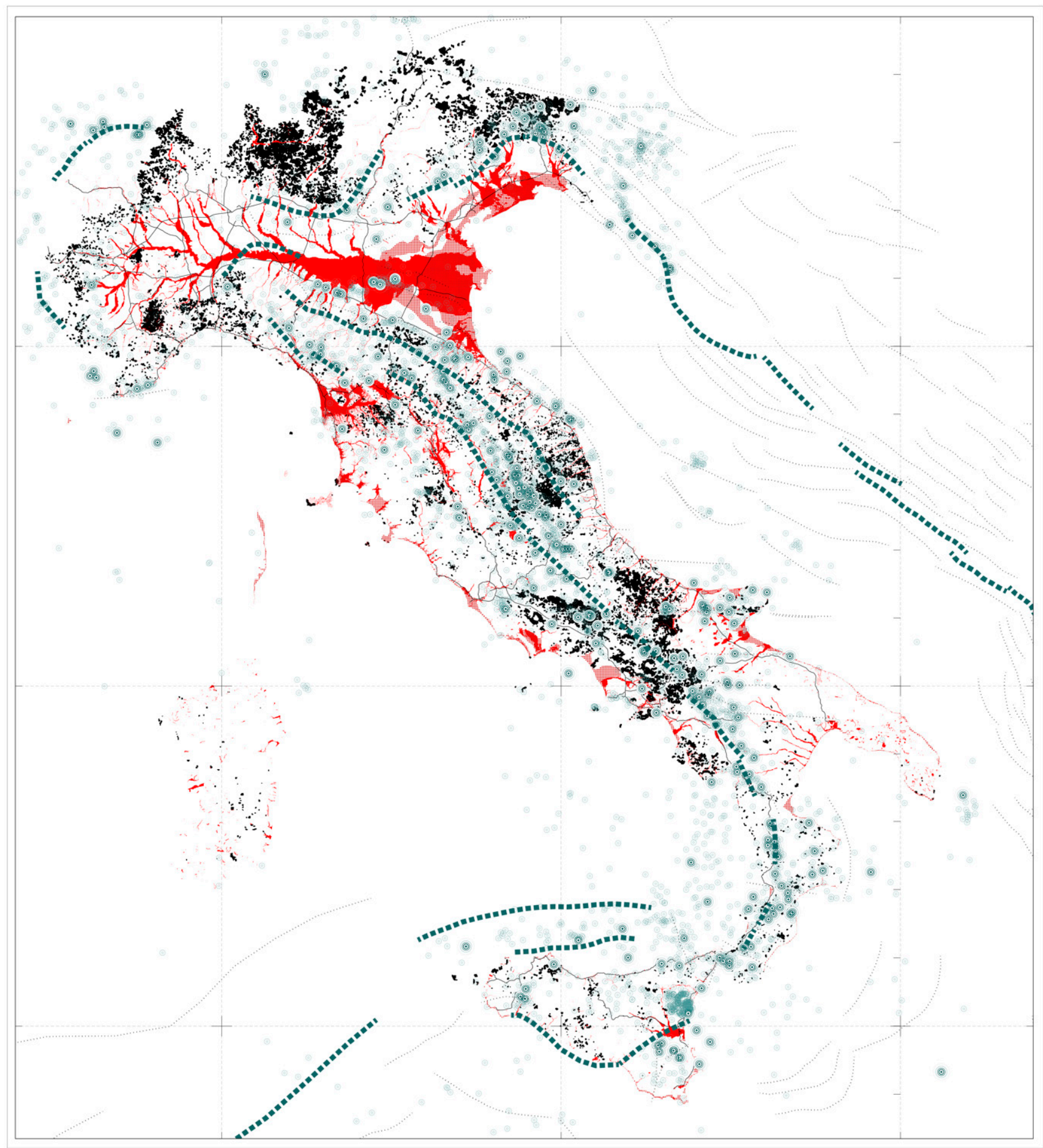

Figure 4. Map C-Extreme events of a catastrophic character (hydraulic, hydrogeological, seismic).

In this map we find:

- Areas subject to flooding and overflow risk, represented with red polygonal surfaces

- Areas subject to SLR and salt wedge advance, represented with polygonal surfaces in dotted red;

- $\quad$ Areas subject to landslide, represented with black polygonal surfaces;

- Earthquakes from the year 1000 to 2014 of Richter magnitude more than 5, represented with large concentric circles in dark turquoise; the earthquakes of lower than 5 degrees on the Richter scale are represented with small circles of light turquoise. 
- Seismogenic faults, represented in blue hatching (main faults) and black (secondary faults).

\subsection{Overlapping the Data}

In next frames we will see the result of the overlapping of the first three maps. The result describes an expansion without reusing previous consumed and abandoned soil. The comparison between the two phenomena highlights at least two possible geographies, which correspond to many themes of transformation (Figure 5).

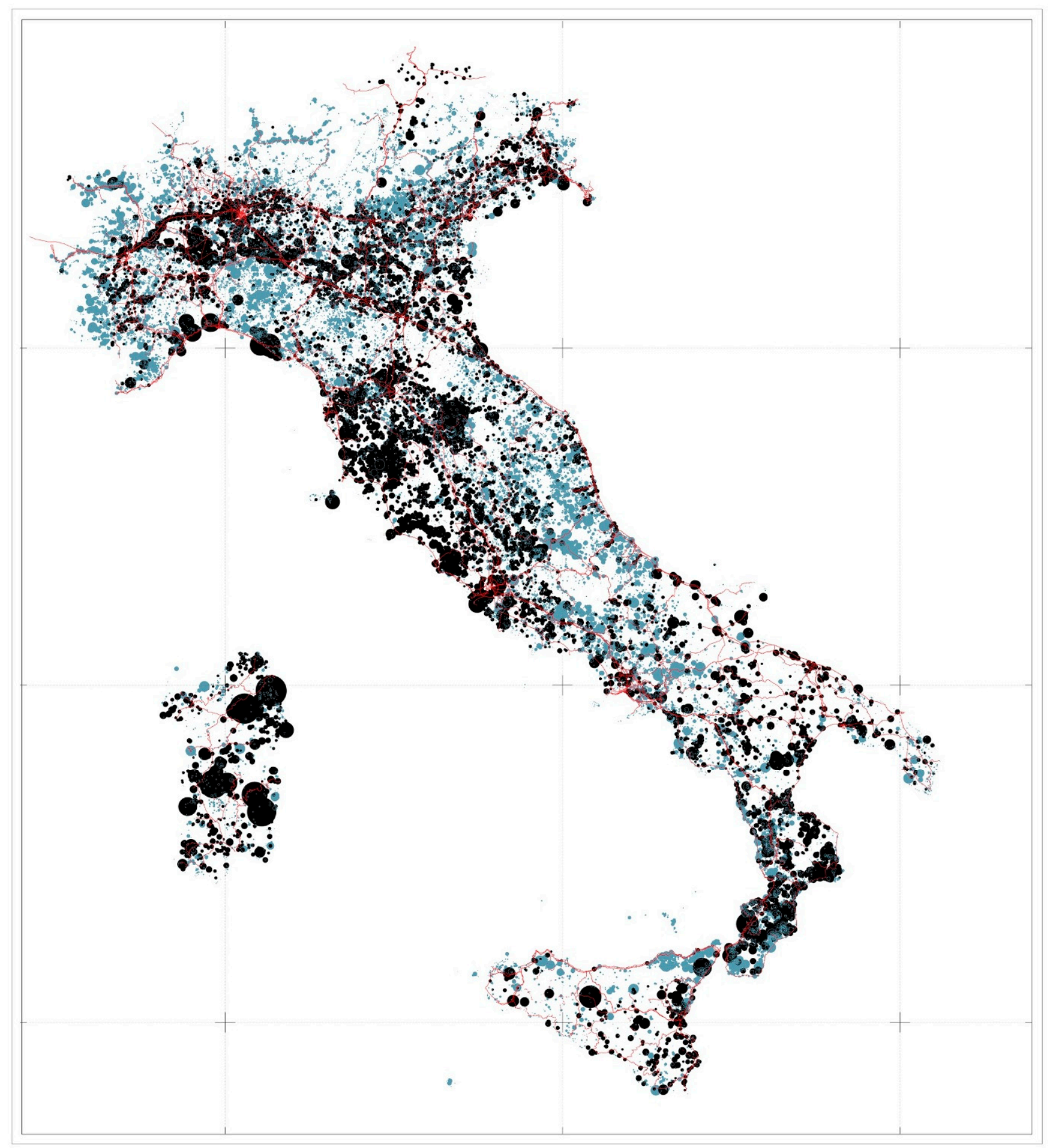

Figure 5. Map AB-Soil consumption and abandonment. 
The first of these geographies illuminates the same urban areas in which the real estate market has been most dynamic; this is most evident around the large cities of the Po Plain, such as the metropolitan area extending from Milan to Brescia via Bergamo, or the conurbation extending between Padua, Venice, and Treviso. In these contexts, it is possible to observe how the phenomena of soil consumption and unused land coincide; unused land is sometimes an expression of abandonment, sometimes of buildings under construction, and sometimes of real estate projects begun but never completed. The second describes a geography of abandonment, coinciding with inland and less accessible areas, more evident in the Alps and Apennines, which is particularly intense in Apulia and Sicily. In this geography, unused buildings more often correspond to abandoned buildings and entire territories.

Map BC-Soil consumption and extreme events. This map demonstrates a geography of correspondence between this expansion and the increase in hydraulic and hydrogeological phenomena, but not in seismic ones. On analysis of the maps, we can recognize empirically a geographical coincidence between the expansion of urbanization and the risk of flooding. Although these correlations do not necessarily show that a cause-effect relationship exists between the phenomena, it is possible to state that in the absence of radical changes in spatial policy, disaster risks will be exacerbated by climate change in the same areas where the housing market has been more dynamic. In Figure 6 we have subtracted seismic and hydrogeological events to mark the dominant relationship between areas of soil consumption and hydraulic risk (Figure 6).

The effects of intense meteorological events interspersed with long periods of drought have made the first and most evident consequences of climate change on Italian territory evident, albeit in an empirical way. Analyses of the frequency and intensity of rainfall on Italian territory and the analysis of the return times of rainfall values show an increase in intense phenomena and the extent of the transformations underway.

Map AC-Abandonment and extreme events. The third map provided us with an interesting alternative figure to $\mathrm{BC}$. In this map the seismic effects measured at the Mercalli scale also show a linear increase in the areas of abandonment. This occurs with the same average number of earthquakes before and after, both locally and on a national country scale. Thus, there is a geographical correlation between the historical incidence of earthquakes and abandoned areas. The seismic risk, which is high or very high for $50 \%$ of the Italian landmass, draws a geography that once again especially affects the internal areas of the Alps and Apennines with high intensity in the areas of north-eastern Italy, western Liguria, the northern Apennines (from Garfagnana to Rimini), and in particular along the entire central and southern Apennines, in Calabria and eastern Sicily. This geography encompasses villages, small municipalities, and some large cities, and involves schools, hospitals, and public facilities which in the last century represented an important repository of the welfare state, and which today are in need of care, adaptation, and maintenance. Although it is not possible to state that there is a cause-effect correlation between the phenomena observed, it is possible to put forward some hypotheses: on the one hand, the high risks deriving from the recurrence of seismic phenomena and geological instability may be an important cause of the abandonment of some inland areas; on the other hand, the progressive abandonment of these areas and the consequent lack of territorial maintenance may be the cause of the increase in damage deriving from seismic events, even when they are not expected to be catastrophic. We have subtracted hydraulic and hydrogeological events from the figure in order to mark the dominant relationship between areas of soil consumption and seismic risk (Figure 7). 


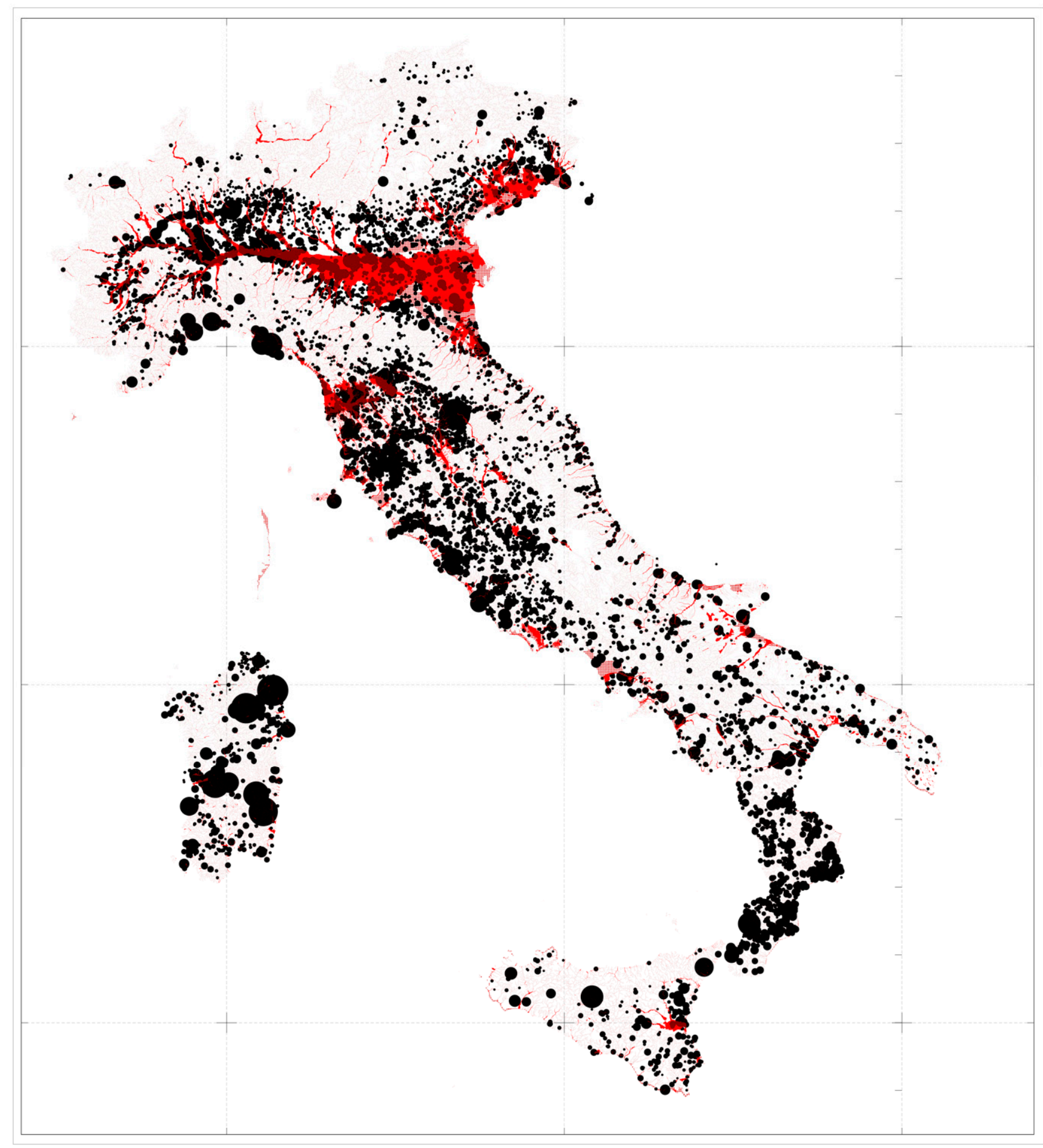

Figure 6. Map BC, detail-Soil consumption and hydraulic extreme events. 


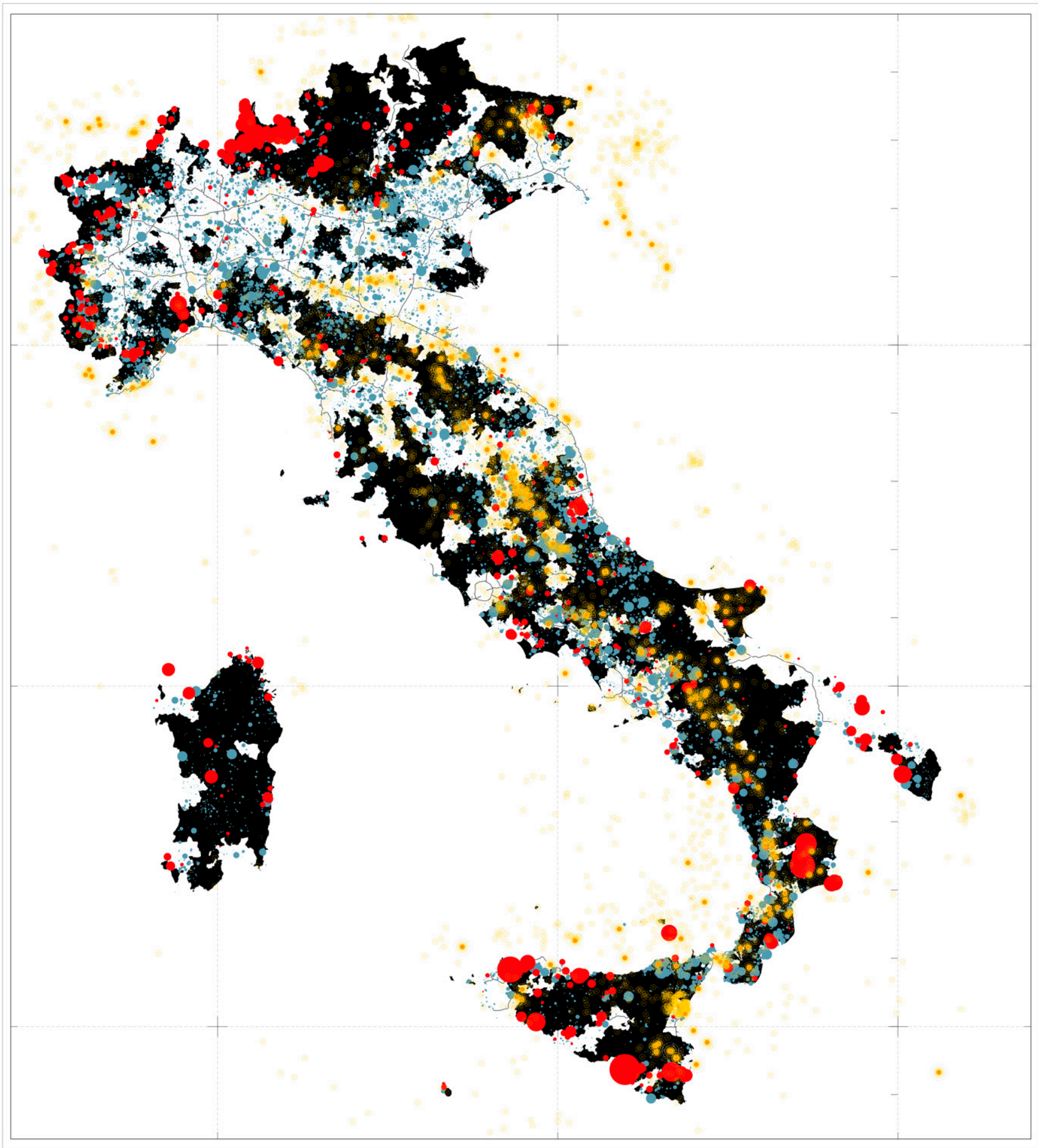

Figure 7. Map AC, detail-Abandonment and seismic extreme events.

\subsection{Testing in Depth}

After the second step, we considered it necessary to investigate the divergences between maps BC and AC with regard to seismic risk. As can be seen in Table 4, the result was a solid confirmation of what was visible from the empirical analysis of the maps. The Poles are the municipalities in economic and population growth. The Peripheries are the municipalities in decline. In the general column we see all events with a Mercalli magnitude of over 2 degrees, which means that the events are capable of causing visible damage each year. We have also subtracted events with a Mercalli magnitude of over 9 degrees from 
the study to focus on the effects of events on buildings and excluding events capable of damaging road systems and the environmental landscape. In the column Poles we see the events above 2 degrees and below 9 degrees that have affected a municipality in this category. In the Peripheries column we see the events in the same vicinity that have affected this category. We have normalized the data with the formula (nEvents Category/total events) to show the progression net of the total events for the year (see Table 4).

Table 4. Determination coefficient of the annual increase in damage per seismic event in 'poles' of aggregation and 'periphery' of the country.

\begin{tabular}{cccccc}
\hline Year. & $\begin{array}{c}\text { Total } \mathbf{n} \\
\text { Events }\end{array}$ & $\begin{array}{c}\mathbf{n} \text { Events in } \\
\text { Poles } \mathbf{2}<\mathbf{x}<\mathbf{9}\end{array}$ & $\begin{array}{c}\text { Poles Events } \\
\text { Normalized }\end{array}$ & $\begin{array}{c}\text { n Events in } \\
\text { Peripheries } \\
\mathbf{2}<\mathbf{x}<\mathbf{9}\end{array}$ & $\begin{array}{c}\text { Peripheries } \\
\text { Events } \\
\text { Normalized }\end{array}$ \\
\hline 2007 & 712 & 433 & 0.608 & 268 & 0.376 \\
2008 & 2216 & 1525 & 0.688 & 573 & 0.259 \\
2009 & 31,504 & 6650 & 0.211 & 5362 & 0.17 \\
2010 & 15,136 & 2462 & 0.162 & 1892 & 0.125 \\
2011 & 21,639 & 3201 & 0.148 & 3186 & 0.147 \\
2012 & 83,115 & 19,084 & 0.23 & 6902 & 0.083 \\
2013 & 27,276 & 5652 & 0.207 & 3493 & 0.128 \\
2014 & 17,799 & 3016 & 0.169 & 2299 & 0.129 \\
2015 & 14,226 & 2296 & 0.161 & 1900 & 0.134 \\
2016 & 47,914 & 9888 & 0.206 & 6439 & 0.134 \\
2017 & 24,372 & 3674 & 0.151 & 2592 & 0.106 \\
\hline
\end{tabular}

The poles have a non-linear trend that is correlated to the total events. The pole's coefficient of determination is not at all significant. The periphery class has a progression with a considerably more solid coefficient of determination. In short, we can conclude our examination of the results by mathematically certifying a strong correlation between abandonment of the Inner Areas and an increase in earthquake damage. This is an important finding because it allows us to overcome the simple correlation between climate change and increased damage. This coefficient provides a scientific confirmation of the relationship between the decrease of inhabitants and the increase of damage caused by extreme events.

\section{Discussion}

The research allows us to shed light on the processes of abandonment and densification that began in Italy a long time ago. The phenomenon of decades-long migration whereby large parts of the population move from the inner areas to the most productive areas of the country is well known and widely analyzed. However, this research refines the reading of the phenomenon by showing the processes and flows of production of waste areas, both in the inner areas and in the expanding areas themselves, which change morphologyconsuming soil while not generating surplus soil.

As Italian cities have expanded, entire buildings, office centres, market streets, manufacturing areas, and polluted territories have been left empty, abandoned, or underused. The great building cycle of expansion, which is now in a phase of intense deflation, has not only consumed substantial new portions of land, removing it from agriculture use, but it has also deposited waste of different types and sizes on the ground, which currently introduces some possible geographies of waste and, through this, possible recycling strategies. From the analysis of the results, we discover that after the sixth building cycle, the phenomenon of soil consumption has been superimposed by processes of degradation of other parts of the territory already urbanized in previous eras, highlighting situations that tell us of conditions of disuse or underuse more often than abandonment.

With this cartographic systematization, the research has made it possible to recognize two new relevant points in the reading of the country. The first of these concerns the relationship 
between urban and territorial transformations and the increase in meteorological impacts. In the face of this, in Italy, there appear to be serious shortcomings in both the policies in place (which are, in almost all cases, of a voluntary and emergency nature) and the territory, where the urban grid and the existing infrastructural support are made fragile by specific conditions: a weak hydrographic network and an increasingly impermeable soil. It is no coincidence that many of the territories affected by news events are located in the most populated regions with the highest rate of waterproofing in the whole of Italy. In Italy, the municipalities affected by landslide and hydraulic hazard are $88.3 \%$ of the total, covering about 57 million inhabitants who are thus threatened by hydrogeological instability.

The third and most significant element recognized by the analysis concerns a strong connection, in terms of vulnerability, between seismic risk and population concentration. This indicates the need for an extensive and urgent recycle of the welfare infrastructures and workplace institutions of Italy. This process of abandonment and increased damage, if not countered, can only have a worsening spiral effect, in which each impact leads to abandonment, and each abandonment causes the severity of subsequent disasters. However, this is not limited to creating localized damage: on the one hand, because the most important national arteries and corridors (as well as all the European corridors that cross Italy) pass through these areas; on the other, because the lack of maintenance of mountain slopes has impacts on the entire downstream hydraulic system, where the most urbanized areas of the country are concentrated.

While the devastation and damage caused by the hydrogeological risk have made evident the potential consequences of neglect in the maintenance of the hydraulic network and of the cultivated slopes in mountain and hill areas, these same facts too often risk the overshadowing of another aspect that is inherent to changes in the weather patterns and that will be all the more evident in the years to come: the link between the abandonment of inland areas and the increase in hydraulic and hydrogeological damage on the poles, and on production and logistics systems. The local impossibility of maintenance will lead on the one hand to the impossibility of crossing the Country, and on the other hand to the increase of uncontrolled floods. Basically, the progression coefficient in the periphery class shows that it is impossible to resolve the disaster risk here without a widespread project to increase residential occupation. This observation is important because it shows how, in Italy, environmental and risk issues lead us to establish a close relationship between metropolitan and inland areas, where the maintenance of one is also instrumental to the safety of the other.

The same results encourage us to take a holistic look at the entire country system, going beyond the sectoral logic of the territorial project, to observe the themes of climatic risk in deep connection with seismic risk and with maintenance and urban development policies. The main outcome of the research is perhaps a confirmation of how, in order to make the Italian system safe, it is not possible to think of a strategy of large aggregation centres in the plains, assisting and supporting the market with ad hoc financing. In fact, it is necessary to rethink the value and the tools of the strategy for the internal areas. This strategy must conceptualize the minor elements of the Italian landscape as the centrality of a single security project. It must start from the development of infrastructures and economies able to restore a widespread habitability and attractiveness to the territory.

The research presented here has two conscious limits. The first, linked to the amount of data analyzed, is that of developing a rationale on a national scale that renounces an interpretation of the local differences of these processes. This limitation could be overcome by subsequent in-depth research that gives a picture of certain regions that are particularly illustrative of the phenomena identified. The second, as is often the case with research into processes in the era of climate change, is the availability of data only from the last 20 to 30 years. This can be overcome (also as a form of control on the accuracy of this research) in 5 to 10 years' time, in order to assess the trend of what is recognized here for the first time.

A particular merit of the research, however, is its replicability in all the countries where data are collected from public, open, and credible sources, providing an important tool to 
recognize dangerous phenomena where they have not been recognized and controlled in the processes of combatting climate change.

\section{Bullet Point Summary of Outcomes}

- Building expansion in the sixth cycle (1990-2006) consumed land without significantly reclaiming the main brownfield sites.

- The subsequent deflationary phase of the construction market (2007-2017) has led to an increase in the speed of abandonment of large areas of the country.

- Hydraulic and hydrogeological events are causing increasing damage throughout the entire country.

- Seismic events have led to damage of increasing intensity, but only in areas where permanent residence has decreased, with a very significant coefficient of determination.

- A downward spiral is recognizable between decreasing permanent residence and a general increase in impacts, not only those related to climate change.

- We can expect an exponential increase of high-impact events in the plain poles if there is no profound transformation of the national climate strategy due to this spiral.

- We can also, for the same reason, expect a collapse of major logistical and production systems due to the collapse of these local transit systems between the poles.

\section{Conclusions}

The article demonstrates scientifically, with a large number of data, the relationship between a reduction in the number of inhabitants and an increase in the damage caused by disasters in low attractive areas. The article also demonstrates the relationship between the expansion of cities in the most attractive areas of the country and the increase of hydraulic risk in these same cities. The serious seismic risk in Italy, and the increase of climaterelated disasters, underline the need for a comprehensive review of national programs and policies in order to avoid the abandonment of peripheral areas and the uncontrolled expansion of centres of aggregation. In order to develop effective territorial projects and policies able to combat the environmental challenges that await us, it is necessary to adopt a synoptic image of the fragility of the Italian system. This image must be constructed by superimposing non-homogeneous phenomena such as urban development, abandonment, and territorial risks. This image is fundamental for developing a project for a resilient country: it can reorient our view and approach to the geographies on which to concentrate projects and policies (e.g., maintenance and combatting the abandonment of inland areas). It should also reorient the policies of the construction market in the next building cycle in the direction of safeguarding and maintaining the territory. This article alerts us to the need to redirect Italy's development and resilience projects starting from a redevelopment of the inner areas and considers living as the first engine and the only security process really capable of taking care of the territory.

Author Contributions: Conceptualization, M.B. and L.F.; methodology, M.B.; formal analysis, M.B. and L.F.; investigation, M.B. and L.F; writing —original draft preparation, M.B. and L.F.; visualization, L.F.; project administration, L.F. All authors have read and agreed to the published version of the manuscript.

Funding: This research was funded by EU 2014-2020 Interreg V-A Italy-Croatia CBC Programme by STREAM-Strategic development of flood management Project. Project number: 10249186.

Institutional Review Board Statement: Not applicable.

Informed Consent Statement: Informed consent was obtained from all subjects involved in the study.

Data Availability Statement: Not applicable.

Conflicts of Interest: The authors declare no conflict of interest. 


\section{References}

1. CRESME. Costruzioni 2011-2015. 2011. Available online: http://www.cresme.it/it/rapporti (accessed on 1 April 2021).

2. Lanzani, A.S.; Zanfi, F. Un territorio ibrido e complesso, a un bivio evolutivo. In Quando L'autostrada non Basta. Infrastrutture, Paesaggio e Urbanistica nel Territorio Pedemontano Lombardo; Lanzani, A.S., Ed.; Quodlibet: Macreta, Italy, 2013.

3. ISPRA, Annuario dei Dati Ambientali-Edizione 2019, 89/2020. 2020. Available online: https://annuario.isprambiente.it/ (accessed on 1 March 2021).

4. UNISDR. Global Assessment Report on Disaster Risk Reduction-Making Development Sustainable; United Nations Office for Disaster Risk Reduction (UNISDR): Geneva, Switzerland, 2015.

5. Magnaghi, A. Il Progetto Locale: Verso la Coscienza di Luogo; Bollati Boringhieri: Torino, Italy, 2013.

6. Fields, B.; Thomas, J.; Wagner, J.A. Living with Water in the Era of Climate Change: Lessons from the Lafitte Greenway in Post-Katrina New Orleans. J. Plan. Educ. Res. 2016, 37, 309-321. [CrossRef]

7. Bertin, M.; Musco, F.; Fabian, L. Rethinking planning hierarchy considering climate change as global catastrophe. Clim. Risk Manag. 2020, 30, 100252. [CrossRef]

8. Blakely, E.J. Recovery of the soul: Rebuilding planning in post-Katrina New Orleans. Hous. Policy Debate 2012, 22, 117-131. [CrossRef]

9. Finn, D.; Chandrasekhar, D.; Xiao, Y. A Region Recovers: Planning for Resilience after Superstorm Sandy. J. Plan. Educ. Res. 2019. [CrossRef]

10. Olasky, M. The Politics of Disaster: Katrina, Big Government, and a New Strategy for Future Crises; W Pub Group. Thomas Nelson: Nashville, TN, USA, 2006.

11. Campanella, T.J. Urban Resilience and the Recovery of New Orleans. J. Am. Plan. Assoc. 2006, 72, 141-146. [CrossRef]

12. Birch, E.; Wachter, S. Rebuilding Urban Places after Disaster: Lessons from Hurricane Katrina; University of Pennsylvania Press: Philadeplphia, PA, USA, 2006.

13. Olshansky, R.B.; Johnson, L. Clear as Mud: Planning for the Rebuilding of New Orleans; Routledge: London, UK, 2017.

14. Russo, M.; Fabian, L.; Morello, E.; Musco, F. La resilienza al Cambiamento Climatico Come Paradigma dell'Agenda Urbana; Il Mulino: Bolonga, Italy, 2017; ISBN 9788815267672.

15. Meyer, P.B.; Schwarze, R. Financing climate-resilient infrastructure: Determining risk, reward, and return on investment. Front. Eng. Manag. 2019, 6, 117-127. [CrossRef]

16. Meyer, P.B. Fitzgerald: Greenovation: Urban Leadership on Climate Change. J. Am. Plan. Assoc. 2021, 87, 148-149. [CrossRef]

17. Magnabosco, G.; Bertin, M.; Fabian, L. Adaptation. A methafor for the age of climate change. In AESOP 2019 Conference-Book of Papers; IUAV: Venice, Italy, 2019; ISBN 978-88-99243-93-7.

18. Fabian, L.; Munarin, S. Re-Cycle Italy; LetteraVentidue: Siracura, Italy, 2017.

19. Berke, P.; Cooper, J.; Aminto, M.; Grabich, S.; Horney, J. Adaptive Planning for Disaster Recovery and Resiliency: An Evaluation of 87 Local Recovery Plans in Eight States. J. Am. Plan. Assoc. 2014, 80, 310-323. [CrossRef]

20. Berke, P.R.; Song, Y.; Stevens, M. Integrating Hazard Mitigation into New Urban and Conventional Developments. J. Plan. Educ. Res. 2009, 28, 441-455. [CrossRef]

21. Brown, D.; Platt, S.; Bevington, J. Disaster Recovery Indicators. Cambridge, MA, USA, 2010. Available online: https://www. carltd.com/sites/carwebsite/files/CAR\%20Brown\%20Disaster\%20recovery\%20Indicators.pdf (accessed on 1 April 2021).

22. Forino, G.; Von Meding, J.; Brewer, G.J. A Conceptual Governance Framework for Climate Change Adaptation and Disaster Risk Reduction Integration. Int. J. Disaster Risk Sci. 2015, 6, 372-384. [CrossRef]

23. Birkmann, J.; von Teichman, K. Integrating disaster risk reduction and climate change adaptation: Key challenges-scales, knowledge, and norms. Sustain. Sci. 2010, 5, 171-184. [CrossRef]

24. Russo, M. Resilienza e ricerca per lo sviluppo sostenibile. In Transizioni. Conoscenza e Progetto Climate Proof; D'Ambrosio, V., Rigillo, M., Eds.; Napoli: Clean, Italy, 2021.

25. Russo, M.; Attademo, A. Il metabolismo del rischio. In Geografie del Rischio. Nuovi Paradigmi per Il Governo del Territorio; Galderisi, A., Di Venosa, M., Fera, G., Menoni, S., Eds.; Donzelli: Roma, Italy, 2020.

26. Russo, M. Ripensare la resilienza, progettare la città attraverso il suo metabolism. Techne 2018, 15, 39-44.

27. Russo, M. Circular economies and regenerative for the city: Ecology, resilience and metabolism of the urban waste areas. Circ. Econ. Regen. City Ecol. Resil. Metab. Urban Waste Areas 2017, 102-105. [CrossRef]

28. ANCE/CRESME, Primo Rapporto ANCE/CRESME, LO STATO DEL TERRITORIO ITALIANO 2012 Insediamento e Rischio Sismico e Idrogeologico. Roma, 2012. Available online: www.ance.it/docs.docDownload.aspx?id=9182 (accessed on 1 May 2021).

29. Coppola, A.; Lanzani, A.S.; Zanfi, F.; Del Fabbro, M.; Pessina, G. Ricomporre i Divari. Politiche e Progetti Territoriali Contro le Disuguaglianze e per la Transizione Ecologica; Il Mulino: Bologna, Italy, 2021.

30. SNAI. Strategia Nazionale per le Aree Interne: Definizione, Obiettivi, Strumenti e Governance. Documento Tecnico Collegato Alla Bozza di Accordo di Partenariato Trasmessa Alla CE il 9 Dicembre 2013; Agenzia per la Coesione territorial: Roma, Italy, 2013.

31. De Rossi, A. Riabitare l'Italia: Le Aree Interne tra Abbandoni e Riconquiste; Donzelli Editore: Torino, Italy, 2019.

32. Carrosio, G. I giovani e la crisi socio-ecologica: Quale welfare per riabitare le aree interne? In Di Fronte al Futuro. I Giovani e le Sfide Della Partecipazione; Delli Zotti, G., Blasutig, G., Eds.; L'Harmattan Italia Editore: Torino, Italy, 2020. 
33. Carrosio, G.; De Renzi, A. Nelle aree interne: Una corretta gestione e valorizzazione del capitale natural. In Ricomporre $i$ Divari. Politiche e Progetti Territoriali Contro le Disuguaglianze e per la Transizione Ecologica; Coppola, A., Lanzani, A.S., Zanfi, F., Pessina, G., Eds.; Il Mulino: Bologna, Italy, 2021.

34. Camagni, R.; Borri, D.; Ferlaino, F. Per un concetto di capitale territorial. Crescita e Svilupp. Reg. Strum. Sist. Azioni 2009, 66-90. [CrossRef] 